\title{
Small ruminant lungworms: Parasite detection, identification and prevalence estimation in three districts of South Wollo, Ethiopia
}

\author{
Tefera Kassa ${ }^{1}$, Tewodros Alemneh ${ }^{2}$ and Dawit Akeberegn ${ }^{2}$ \\ 'Borena Woreda Livestock Association and Development Office, Borena, South Wollo, Ethiopia. \\ ${ }^{2}$ Faculty of Veterinary Medicine, University of Gondar, P. O. Box 196, Gondar, Ethiopia. \\ ${ }^{*}$ Corresponding author. Email: tedyshow@gmail.com
}

Copyright ( 2017 Kassa et al. This article remains permanently open access under the terms of the Creative Commons Attribution License 4.0, which permits unrestricted use, distribution, and reproduction in any medium, provided the original work is properly cited.

Received 4th January, 2017; Accepted 26th January, 2017

\begin{abstract}
The prevalence, species, age, sex and seasonal variation of lungworm infection in small ruminants were studied using Coproscopic and Postmortem examinations in Three districts of South Wollo: Kombolcha, Dessie and Kalu. Faecal samples were collected from 586 sheep and goats of all age groups (below 6 months, 6 months to 2 years, 2 to 4 years and above 4 years) and both sexes. Modified Baermann technique was used for extraction of $L_{1}$ larvae from the faeces. Post-mortem examination had also been done on 98 animals in Dessie abattoir during the study period. An overall prevalence of $31.2 \%$ and $7.1 \%$ were detected by faecal and post-mortem examinations, respectively. Significant difference $(\mathrm{p}<0.05)$ was found between areas of different altitude with an infection rate of $47.5 \%, 35.5 \%$ and $28.5 \%$ in Dessie, Kombolcha and Kalu respectively. Factors such as age, species of parasite, season and origin of animals showed significant differences $(p<0.05)$ on the prevalence of small ruminant lungworm infection. However, there was no significant difference ( $p>0.05$ ) observed among sex, species, management system and body condition score of animals. Due to its impact on production, emphasis should be given for the control and prevention of lungworm infection in the areas.
\end{abstract}

Key words: Lungworm, prevalence, small ruminant.

\section{INTRODUCTION}

Sheep and goats provide as much as $30 \%$ of the meat and milk consumed in sub-Saharan Africa and is found on smallholdings throughout the continent. Production and marketing of sheep and goats and their products are a vital source of income, especially for small holders who do not have access to credit or farm income. Due to the small size, high reproductive capacity and rapid growth rate, small ruminants provide a more flexible short-term investment than cattle. Yet these species have received much less attention from research and development agencies than cattle (ILCA, 1990).

Helminthes parasites of ruminants are ubiquitous, with many tropical and subtropical environments of the world providing nearly perfect conditions for their survival and development. Although, these parasites are widely prevalent, the clinical signs they cause in infected animals can be less obvious than signs of other livestock diseases. Partly for this reason, infections with gastro-intestinal and other helminthes parasites are among the most neglected areas of veterinary care in much of the developing world. High prevalence rates of the infection result in poor production and unthriftiness (Hansen and Perry, 1994).

Among many constraints, which limit productivity in livestock populations, parasites are of major importance (Mboera and Kitalyi, 1992). Endo-parasites are important problem for sheep and goat farmers causing gastroenteritis in these animals in Africa and throughout the world (ILCA, 1991).

Dictyocaulidae and/or certain Metastrongylidae are known to exist in East Africa (Ethiopia, Kenya and Tanzania) and South Africa (Torncy, 1989). Endoparasites, including Dictyocaulus filaria are major causes 
of mortality in the Ethiopian highlands (ILCA, 1993, 1992). About $50 \%$ of mortality in sheep in farms of Ethiopian highlands is caused by pneumonia and endo-parasites (ILCA, 1990). Control of these parasites is essential for harnessing the potential of small ruminant production. For proper control to be instituted, however, diseases and their dynamics must be known. At our present state of knowledge of parasitic diseases, it is difficult and even dangerous to lay down rigid rules for their control which are applicable to all regions. For this reason a study of epidemiology of each parasitic disease should be limited to small areas (Rodostitis et al., 1994). The incidence of parasitic diseases, including respiratory helminthosis varies greatly from place to place depending on the relative importance of many of the factors. In this regard, very few studies were conducted so far pertaining to respiratory helminths of small ruminants in Wollo, Amhara National Regional State, Ethiopia.

The present study was undertaken to find out the prevalence and species variation on respiratory helminths of small ruminants in different zones of Wollo, in Amhara Regional State, Ethiopia.

\section{MATERIAL AND METHODS}

\section{Study area}

\section{Topography and climate}

The study was conducted at Kombolcha town, which is found in South Wollo administrative Zone of Amhara Regional State in North Eastern Ethiopia. The study area is located $376 \mathrm{~km}$ North of Addis Ababa with $11^{\circ} 084^{\prime} 49^{\prime \prime} \mathrm{N}$ latitude and $0.39^{\circ} 737^{\prime} 46^{\prime \prime} \circ \mathrm{E}$ longitude at an altitude of 1840 meter above sea level (msl) (Figure 1). The Kombolcha town experiences a bi-modal rainfall, the short rainy season occurs usually from March to May while the long rainy season occurs from June to August. The minimum and maximum mean annual rainfall in and around Kombolcha ranges from 750 to $900 \mathrm{~mm}$. The average minimum and maximum daily temperature during short and long rains are $23.9^{\circ} \mathrm{C}$ and $11.7^{\circ} \mathrm{C}$ respectively and the relative humidity of the area varies from $23.9 \%$ to $79 \%$.

\section{Vegetation}

The nature of vegetation varies from savannah grass land, bushes and dense shrubs to huge trees like Juniper, Acacia, Hagina abysinica (Kosso), Cordial africana. Vegetation dries off during the dry season in almost all regions except on high land grazing areas and revival of vegetation with the commencement of rain on the low lands.

\section{Farming system in the area}

The type of farming in the area is mixed crop to livestock production system. Small ruminant production in the area is an integral component of the traditional farming system. The main livestock grazing land available to animals are swampy water-lodged areas, forest margin, hilly tops and mountain sides, stony and infertile lands, and road sides. According to the Agricultural Office report (2010), livestock population in the area comprises of $1,826,900$ cattle, $1,401,470$ sheep, 980,750 goats, 262,420 donkeys, 3,420 camels and 2,046,710 poultry.

\section{Study animals and their management}

The animals used in this study are owned by subsistence farmers and small-scale private farms. The breeds of sheep and goats in the study area are Menz and Small East-African breeds respectively.

\section{Management}

Sheep and goats are traditionally kept on extensive management system. These animals are maintained in small household flocks of mixed ages usually less than 10 animals in lowlands but 20 to 50 or more at the extreme of the high land areas.

Sheep and goats are kept close to the village and they are allowed to graze native pastures on grasslands. Supplementary feeding and forage conservation is not practiced, however, after harvest when there is no risk of damage to crops, animals may have access to hay, stubbles and other leftovers of the year's harvest. Watering is only once at the middle of the day from the nearby streams, rivers or shallow wells.

\section{Study design}

Cross-sectional study design was carried out to determine the prevalence of small ruminants' lung worm infection in selected three districts of south Wollo.

\section{Sample size}

The sample size required for this study was determined depending on the expected prevalence of small ruminant lung worm infection and the desired absolute precision according to Thrusfield (2005) by the following formula.

$\mathrm{n}=\frac{1.96^{2} \text { Pexp }(1-\text { Pexp })}{\mathrm{d}^{2}}$

Where: $\mathrm{n}=$ required sample size; $P_{\exp }=$ expected prevalence $(50 \%) ; d=$ desired absolute precision (5\%).

According to the above formula, the calculated sample size was 384. However, in order to increase the accuracy the number of sampled small ruminants was 586 . 


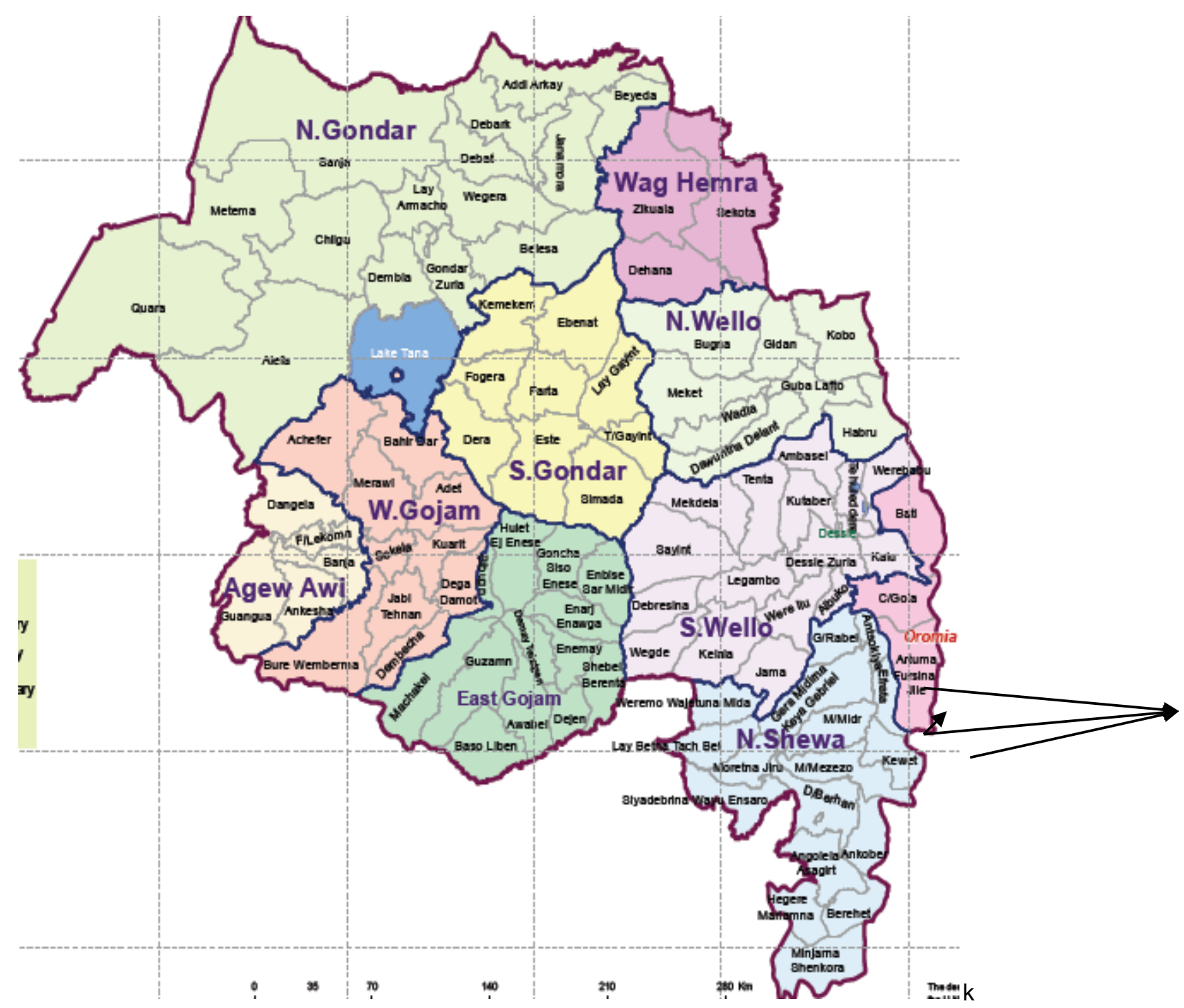

Figure 1. Map of Amhara Region; the arrow on the right indicates the study areas. (Source: http://en Wikipedia.Org/wiki/ Amhara-Region, 2009).

\section{Sampling procedure}

In this study, the area was classified into three districts (Woredas) which are Dessie, Kombolcha, and Kalu. The study subjects were managed under extensive and semiintensive production system.

\section{Sample collection}

Faecal sample were collected directly from the rectum of selected animals in screw capped glass bottle (universal bottles) and packed in ice box. While collecting faecal sample, the species of the animals, sex, age, management, date of sampling and the area were properly recorded.

\section{Diagnosis}

\section{Laboratory diagnosis}

In the laboratory, $2.5 \mathrm{~g}$ of fresh faeces was weighed from each sample for the extraction of $L_{1}$ larvae using modified Baermann technique. These were enclosed in gauze fixed on to a string rod and submerged in a clean glass tube filled with warm water. The whole apparatus was left for 2 to 4 hours. The larvae then leave the faeces, migrate through the gauze and settle at the bottom of the glass. After siphoning of the supernatant, the sediment was examined under the low power of the microscope. When positive, a drop of $1 \%$ iodine solution was used to immobilize the larvae for identification of species, otherwise 
otherwise it was registered negative for lung worm infection (Fraser, 1991; Urquhart et al., 1994).

\section{Post mortem examination}

The lungs were palpated for presence of metastrongyloid nodules, which are usually grayish white in color. If present, they are trimmed of and worms extracted from the tissue by gentle compressing a small non calcified nodule or part a large nodule between two glass slides, and then teasing the worms away from the tissue with thumb forceps. To collect all worms at the bottom of the beaker added with that of the previous and transferred to glass beakers containing saline. The air passages were opened starting from the trachea down to the small bronchi with fine blunt pointed scissors to detect parasites; visible worms were then removed from the opened lungs and transferred to glass beakers containing saline. The worms collected were identified and recorded (ILCA, 1991; Fraser, 1991).

\section{Data analysis}

The results were analyzed in relation to sex, species of animal, age, management, origin, body condition, species of lungworms and season. Animals were categorized in to four age groups. Age group I (<6 months), age group II (6 months to 2 years), age group III (2 to 4 years) and age group IV ( $>4$ years). The data obtained were coded for the above factors and entered in to excel. Then Chi-square was used to compare the prevalence of small ruminants' lungworm infection for possible significance difference. The differences were regarded as significant if $p$-value is $<0.05$ using SPSS.

\section{RESULTS}

\section{Coproscopic examination}

Out of all animals examined, 183 were positive for lungworm infection with an overall prevalence of $31.2 \%$ (Table 1).

There was significant difference on the prevalence of lungworm infection of small ruminants in different districts of south Wollo $\left(x^{2}=41.324, P<0.05, d f=3\right)$. The highest prevalence was recorded in Dessie $(47.5 \%)$ followed by Kombolcha $(35.5 \%)$ while the lowest in Dessie abattoir (7.1\%) (Table 1).

There was no significant difference $(p>0.05)$ on the prevalence of lungworm infection on the basis of species and sex of small ruminants. However, the prevalence was slightly higher in ovine $(31.4 \%)$ and males $(31.8 \%)$ as compared to that of caprine $(31.0 \%)$ and females $(31.0 \%)$ (Table 1).
There was significant difference $\left(x^{2}=11.127\right.$, df $=3$, $p<0.05$ ) on the prevalence of lungworms among the four age groups of small ruminants. The highest prevalence was in group I (61.7\%) and the lowest was in group IV (11.4\%) (Table 1).

There was no significant difference $\left(x^{2} \mathrm{cal}=4.136, \mathrm{df}=\right.$ $2, p>0.05)$ on body condition score of the animals. However, the highest prevalence was noticed in poor $(50 \%)$ and the lowest prevalence in medium (28.2\%) body condition score of the small ruminants. Similarly, there was no significant difference $\left(x^{2} \mathrm{cal}=0.331, \mathrm{df}=1, \mathrm{p}>0.05\right)$ of lungworm infection under different management system. However, the highest prevalence was found in extensive management system (31.8\%) while the lowest prevalence in semi-intensive management system $(29.1 \%)$.

There was significant difference $\left(x^{2} \mathrm{cal}=5.860\right.$, df $=4$, $p<0.05)$ on the prevalence of lungworm infection with species of lungworms. The prevalence was decreased when the age of animals increased in the cases of $M$. capillaries, $P$. rufescens and DFMC infection, but not in case of $D$. filarial infection (Table 2).

There was significant difference $\left(x^{2}=17.660, \mathrm{df}=4\right.$, $p<0.05$ ) on the basis of monthly prevalence of lungworm infections. The result showed that the highest prevalence was recorded in January $(40.1 \%)$ while the lowest in November (19.8\%) (Table 3 and Figure 2).

\section{Post-mortem examination}

A total of 98 lungs from small ruminants slaughtered at Dessie abattoir were examined through post-mortem inspection, of which $7(7.1 \%)$ were positive for lungworm infection. The lungworm species encountered during intact lung incisions during the study period was $D$. filaria with a prevalence of $7.1 \%$ (Table 4 ).

\section{DISCUSSION}

\section{Coproscopic examination}

The current study revealed that the presence of three nematode species parasitizing the respiratory tract of small ruminants with an overall infection rate of $31.2 \%$. These parasites had also been reported in sheep from different climatic areas of the world and from different regions of Ethiopia (Thomson et al., 1988). A similarly high prevalence $(50 \%)$ was recorded in previous study conducted at Kombolcha and Dessie by Teffera 1993. Studies made in other parts of Ethiopia had also underlined the relative importance of this disease in small ruminants. For instance, Wondewosen (1992) had reported $58 \%$ in Assela, Assaye and Alemneh (2015) reported $22.7 \%$ in and around Bahir Dar and Muluken (2009) had reported a prevalence of $18.16 \%$ in Bahir Dar.

The current overall prevalence result almost coincides 
Table 1. The prevalence of lungworm infection in small ruminants on the basis of various factors.

\begin{tabular}{|c|c|c|c|c|}
\hline \multirow{2}{*}{ Factor } & \multicolumn{2}{|c|}{ № of Animals } & \multirow{2}{*}{ Prevalence (\%) } & \multirow{2}{*}{ Chi-square (X2) and $P$-value } \\
\hline & Examined & Positive & & \\
\hline \multicolumn{5}{|l|}{ Species } \\
\hline Ovine & 360 & 113 & 31.4 & \multirow{2}{*}{$\mathrm{X}^{2} \mathrm{cal}=0.011, \mathrm{p}=0.916, \mathrm{df}=1$} \\
\hline Caprine & 226 & 70 & 31.0 & \\
\hline \multicolumn{5}{|l|}{ Sex } \\
\hline Male & 192 & 61 & 31.8 & \multirow{2}{*}{$\mathrm{X}^{2} \mathrm{cal}=0.39, \mathrm{df}=1, \mathrm{p}=0.843$} \\
\hline Female & 394 & 122 & 31.0 & \\
\hline \multicolumn{5}{|l|}{ Age } \\
\hline$<6$ Months & 175 & 108 & 61.7 & \multirow{4}{*}{$\mathrm{X}^{2} \mathrm{cal}=112.651, \mathrm{df}=3, \mathrm{p}=0.00$} \\
\hline $6 \mathrm{M}-2$ years & 204 & 46 & 22.5 & \\
\hline 2 - 4 years & 75 & 14 & 18.7 & \\
\hline$>4$ years & 132 & 15 & 11.4 & \\
\hline \multicolumn{5}{|c|}{ Body Condition } \\
\hline Poor & 20 & 10 & 50.0 & \multirow{3}{*}{$\mathrm{X}^{2} \mathrm{cal}=4.136, \mathrm{p}=0.126, \mathrm{df}=2$} \\
\hline Medium & 188 & 53 & 28.2 & \\
\hline Good & 378 & 120 & 31.7 & \\
\hline \multicolumn{5}{|c|}{ Management System } \\
\hline Extensive & 459 & 146 & 31.8 & \multirow{2}{*}{$\mathrm{X}^{2} \mathrm{cal}=0.331, p=0.565, \mathrm{df}=1$} \\
\hline Semi-intensive & 127 & 37 & 29.1 & \\
\hline \multicolumn{5}{|l|}{ District } \\
\hline Kombolcha & 259 & 92 & 35.5 & \multirow{4}{*}{$\mathrm{X}^{2} \mathrm{cal}=41.324, \mathrm{df}=3, \mathrm{p}=0.000$} \\
\hline Kalu & 130 & 37 & 28.5 & \\
\hline Dessie & 99 & 47 & 47.5 & \\
\hline Dessie abattoir & 98 & 7 & 7.1 & \\
\hline Total & 586 & 183 & 31.2 & \\
\hline
\end{tabular}

Table 2. Prevalence of lungworm species among the four age groups of small ruminants.

\begin{tabular}{lcccccc}
\hline Age & $\begin{array}{c}\text { Total animals } \\
\text { examined }\end{array}$ & $\begin{array}{c}\text { D. filaria } \\
\mathbf{P}(\%)\end{array}$ & $\begin{array}{c}\text { M.capillaries } \\
\mathbf{P}(\%)\end{array}$ & $\begin{array}{c}\text { P. rufescens } \\
\mathbf{P}(\%)\end{array}$ & $\begin{array}{c}\text { DFMC } \\
\mathbf{P}(\%)\end{array}$ & Total P (\%) \\
\hline <6 M & 175 & $56(32 \%)$ & $25(14.3 \%)$ & $2(1.1 \%)$ & $9(5.1 \%)$ & 52.6 \\
6M-2 year & 204 & $25(12.3 \%)$ & $10(4.9 \%)$ & $2(0.98 \%)$ & $1(0.49 \%)$ & 18.6 \\
2-4 years & 75 & $46(61.3 \%)$ & $0(0 \%)$ & $0(0 \%)$ & $0(0 \%)$ & 61.3 \\
$>$ 4 years & 132 & $6(4.6 \%)$ & $0(0 \%)$ & $0(0 \%)$ & $1(0.76 \%)$ & 5.3 \\
\hline
\end{tabular}

$\mathrm{X}^{2}=125.178, \mathrm{df}=12, \mathrm{p}=0.000 ; \mathrm{DFMC}=$ mixed infection with $D$. filarial and $M$. capillaries .

with the previous report of Brook et al. (1986) (27.8\%) in Assela. But it was not similar with the findings of Abdukadir (2009) in the same area who reported higher prevalence $(42.96 \%)$.
This could be due to the fact that the establishment of open air clinic in rural kebeles, increased in numbers of private veterinary pharmacies, increased farmers awareness to deworm their small I ruminants, prevailing 
Table 3. The seasonal variation of small ruminants' lungworm infection.

\begin{tabular}{lccc}
\hline Months & Animals examined & Positive & Prevalence (\%) \\
\hline November & 121 & 24 & 19.8 \\
December & 102 & 34 & 33.3 \\
January & 172 & 69 & 40.1 \\
February & 99 & 35 & 35.4 \\
March & 92 & 21 & 22.8 \\
Total & 586 & 183 & 31.2 \\
\hline
\end{tabular}

$\mathrm{X}^{2} \mathrm{cal}=17.660, \mathrm{p}=0.001, \mathrm{df}=4$.

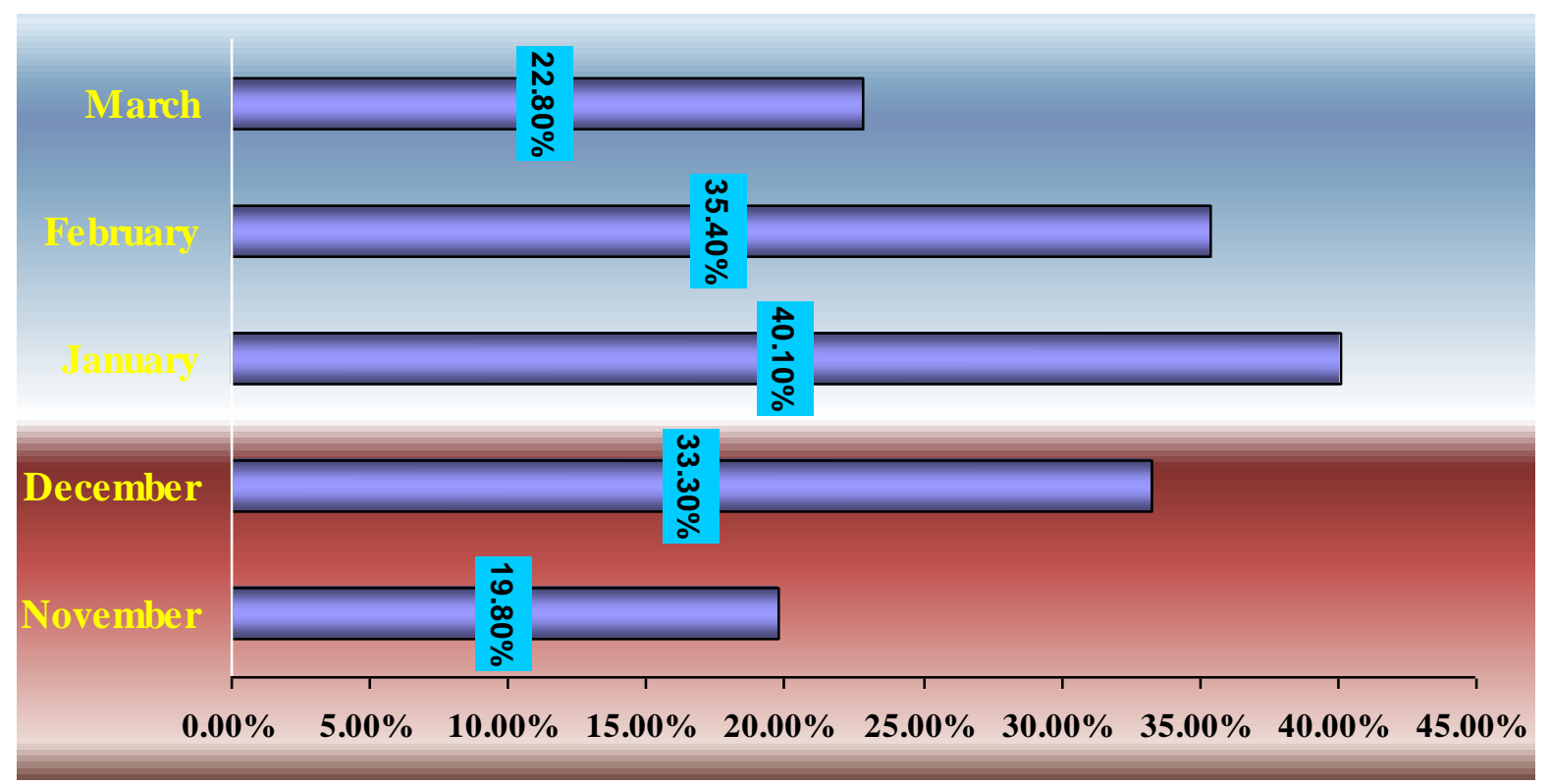

Figure 2. Monthly prevalence of small ruminants' lungworm infection.

Table 4. The prevalence of lungworm species in small ruminants by post-mortem examination.

\begin{tabular}{lccccc}
\hline & \multicolumn{4}{c}{ Adult worm burden $(\mathbf{n}=\mathbf{8 0})$} & \multirow{2}{*}{ Total } \\
\cline { 2 - 5 } & D. filarial & M. capillaries & P. rufescens & DFMC & \\
\hline Positive & 7 & 0 & 0 & 0 & 7 \\
Prevalence & $7.1 \%$ & $0 \%$ & $0 \%$ & $0 \%$ & $7.1 \%$ \\
\hline
\end{tabular}

environmental change and differences in rain fall, humidity, temperature and altitude of kebele's included in the study. The current finding however, disagreed with the previous findings of Eyobe (2008) who reported a prevalence of $72.44 \%$ in Assela. Such variation in infection rate could be attributed to the variation in altitude, rainfall, humidity and temperature differences in different area of the country (Blood et al., 1989).

The finding of $M$. capillaries with $14.3 \%$ prevalence of the total positives in the study area disagreed with the previous reports of Mezgebu (1995) in Addis Ababa
(54.9\%) and Sissay (1996) in Bahir Dar (39.3\%). But this result agreed with the previous reports of Paulos (2000) in Arsi Zone and Mengstom (2008) in Tigray (Atbhi) reported that $D$. filaria was the most prevalent species.

In the present study, the finding of $D$. filaria as the most prevalent when compared to the other species of lungworms in small ruminants might be due to the fact that $D$. filaria has indirect life cycle, took more time to reach the infective stage and after ingestion, larva can appear in faces after several weeks (Soulsby, 1982). The probability of infection, transmission and reinfection with a season 
could much more high when compared with $M$. capillaries and $P$. rufescens. These factors explained that the young (weaning) animals have higher infection rate of $D$. filaria (Mengestom, 2008).

Influence of sex on the prevalence of infection indicated that there was no significant difference $(P>0.05)$ in susceptibility to infection with lungworms. Hence, sex dependant variation was not encountered. This result was not in agreement with the earlier study of Sissay (1996) and Alemu (1999) who reported significant variation in the infection rate of lungworm in male and female, and coincides with Netsanet (1992) in and around D. Birhan and Teffera (Wendewosen, 1992) in and around Dessie and Kombolcha who reported equal susceptibility in both sexes. This might be due to the improper distribution of sample selection between the two sexes (Paulos, 2000) or most of the samples from female sheep and goats were not in preparturient period during the study period (ILCA, 1990; Urquhart et al., 1994). In addition, most males included in the sample were uncastrated and freely mating in the field might also create stress like that of females.

The influences of management system on the prevalence of lungworms indicated that there was no statistically significant difference $(p>0.05)$ between extensive and semi-intensive management systems. This finding was different from Sissay (1996) in and around Bahir Dar, Alemu (1999) in Wollo and Eyobe (2008) in Assela who reported that management had significant difference on susceptibility. The possible reason for the present finding could be due to the fact that grazing in the same pasture and feeding moist pastures for the small ruminants in the area attributed to similarity on susceptibility to lungworm infection between the two management systems.

The influence of body condition on the prevalence of lungworm infection revealed that there was no statistically significant association $(p>0.05)$. The prevalence of lungworm infection on coproscopic examination was found to be higher $(50 \%)$ in animals of poor body conformation than that of well confirmed ones (31.7\%). This finding coincides with Mengestom (2008) who reported that the affected small ruminants, loss of weight cannot be attributed to lungworm infection alone since Hamonchus contortus and other GIT helminthes could be encountered. Poor body condition could be associated with failure to deworm animals or due to lack of feed or nutritional management which lead to lack of resistance to infection and contributed for increased prevalence in poorly conditioned animals.

The monthly dynamics of lung worm infection within the study periods showed that prevalence was higher in January when compared to dry season. This finding coincides with the results of unpublished report of Ferwengle (1995). The survival and development of lungworm larvae was favored by low moisture content and high humidity. For instance, infective larva on pastures minimum during the summer months but reaches peak level during the cooler autumn (Ayalew et al., 1973). Such conditions are obtained after long rainy season (September to November) in Wollo and at high altitude areas.

With regard to age, the prevalence of lungworm infection in small ruminants was found to be higher in young's (weaning) than adults and showed significant difference $(p<0.05)$. This finding was in agreement with Schanzel (1959) who reported that young animals were found to harbor twice as many $D$. filaria than adults. However, disagree with the idea that the intensity of infection by $M$. capillaris was six times higher in adult small ruminants. This was also not in line with Thomson and Orita (1988) who found an increased infection rate in the age of the animals.

In this study, comparing the susceptibility of species of small ruminants, sheep were found slightly more susceptible to lungworm infection than goats. This finding was not in agreement with Assaye and Alemneh (2015) who reported that goats were more susceptible to both initial and challenge infections than that of sheep.

The prevalence of lung worm infection by coproscopic examination was higher in Dessie (47.5\%) followed by Kombolcha $(35.5 \%)$ while the lowest prevalence was recorded in Kalu $(28.5 \%)$. The result showed significant difference $(p<0.05)$. This result was due to the reasons of altitude and temperature variation in three selected areas.

\section{Post-mortem examination}

The observation of the intact lung of slaughtered small ruminants in Dessie town revealed that $7.1 \%$ overall prevalence while the prevalence of coprological finding was $31.2 \%$. This decreased prevalence in post-mortem examination disagreed with the finding of Eyobe (2008) in Assela reported higher prevalence in post-mortem than coprological examination. But, the present finding agreed with the finding of Paulos (2000) in Arsi chilallo who reported higher prevalence in faecal than post-mortem examination.

One of the probable reasons attributed for such difference in the present finding could be those larvae which reach the lungs of small ruminant was not remain in the parenchyma and not become encysted in fibrous nodules. Because, such nodules eggs many be deposited in air passage (Rodostitis et al., 1994). Therefore, the finding of the present study strongly supports that coproscopic examination had wide value in estimating the burden of lung worm infection in small ruminants. Hence, coproscopic examination requires serious cautions. In addition, most sheep and goats brought for slaughter were from rural areas, the probability of deworming might be high. The larvae were found 50 to $100 \mathrm{gm}$ only in faces/pellet of patent cases, otherwise, in the rest phase it might not be dispersed throughout the pellet (Urquhart et al., 1994). 


\section{Conclusion}

The study on lung worm infection of small ruminants by faecal and post-mortem examinations in three districts of south Wollo revealed an overall prevalence of $31.2 \%$ and $7.1 \%$, respectively. The respiratory nematodes $D$. filaria, $M$. capillaries and $P$. rufescens were identified. This high prevalence of verminous pneumonia as the result of these three species was considered as one of the important nematode infection in small ruminants in the study area. It was found that young (weaning) small ruminants were most affected by $D$. filaria, than adults. The prevalence of lung worm infection had no significant association with sex, species of animals, body condition and management in the study area.

\section{CONFLICT OF INTEREST}

The authors declare that they have no conflict of interest.

\section{REFERENCES}

Abdukadir, M. (2009): Prevalence of ovine lung worm infection in and around Kombolcha. DVM Thesis, SVM. Jimma Univesity, Jimma, Ethiopia.

Alemu, S. (1999): Survey of small ruminant lung worms in six district of Wollo, DVM Thesis, AAU-FVM, Debrezeit, Ethiopia.

Assaye, M., Alemneh, T. (2015). Prevalence of Lungworm Infection of Small Ruminants in and Around Bahir Dar City, Amhara Regional State, Ethiopia. Journal of Veterinary Science and Technology, S12, 002. doi:10.4172/21577579.S12-002

Ayalew, L., Frechette, L. J., Malo, R., \& Beauregard, C. (1973). Studies on the Incidence of Dictyocaulus filaria in sheep of Rimouski region. Canadian Veterinary Journal, 14(12), 301303.

Blood, D. C., Rodostitis, O. M., \& Gay, C. C. (1989). veterinary medicine a text book of the diseases of cattle, sheep, pigs, goats and horses. 7th ed. Balilliere Tindal, Pp. 1039-1044.

Brook, L., Fesseha, G., \& Shibru, T. (1986). The seasonal occurrence of D. Filaria (Rudolphi: 1890) in four selected sites of Ethiopia. Ethiopian Journal of Science, 9(1-2), 263-285.

Eyobe, E. (2008). The prevalence of lung worm in ovine in Assla: DVM Thesis, Jimma University, Jimma, Ethiopia.

Ferwengle, S. (1995). Prevalence of ovine Dictyocauliasis in and around Mekele (Tigray), DVM- thesis, FVM. Addis Ababa University Debre Zeit, Ethiopia.

Fraser, C. M. (1991). The Merck veterinary manual. A hand book of Diagnosis Therapy and disease prevention and control for the veterinarians. 7th ed; Merck and co; Inc, Rahway, NIT USA. Pp. 714-717.

Hansen, J., \& Perry, B. (1994): The epidemiology, diagnosis and control of helminthes parasite of ruminants. ILRAD Nirobi Kenya.
ILCA (International Livestock Center for Africa). (1993). ILCA.1992 Annual report and programme highlights. ILCA, Addis Ababa, Ethiopia, Pp. 29-31.

ILCA (International Livestock Centre for Africa). (1990). ILCA Annual Report 1989. ILCA, Addis Ababa, Ethiopia, p. 37.

ILCA (International Livestock Centre for Africa). (1991). ILCA 1990 Annual Report and Programme highlights. ILCA, Addis Ababa, Ethiopia, Pp. 7-10

Mboera, L. E. G. \& Kitalyi, J. I. (1992). Small Ruminant Research and development in Africa. International Livestock Center for Africa, P. 117.

Mengestom, G. (2008). Preliminary study on prevalence of ovine lung worm infection in Addis Ababa and surrounding land areas. DVM Thesis AAU-FVM, Debrezeit, Ethiopia.

Mezgebu, M. (1995). A survey on ovine fascioliasis and lungworm infection in Addis Ababa and the surrounding highland areas. DVM-Thesis, FVM, Addis Ababa University, Debre Zeit, Ethiopia.

Muluken, Y. (2009). Prevalence of ovine lung worm infection in and around Bahir Dar, DVM Thesis,Jimma UniversitySVM,Jimma, Ethiopia.

Netsanet, B. (1992). Study on the prevalence and control of lungworms (Dictyocaulus and Muellerius) in local Ethiopian highland sheep in and around Debre Berhhan. DVM-Thesis FVM., Addis Ababa Univeristy, Debre Zeit, Ethiopia.

Paulos, A. (2000). Importance and Seasonal dynamics of lung worm infections of small ruminants in chillalo area, Arsi zone, DVM Thesis, AAU-FVM Debrezeit Ethiopia.

Rodostitis, O. M., Blood, D. C., \& Gay, C. C. (1994). Veterinary Medicine. A text book of the diseases of cattle, sheep, pigs, goats and horses. 8th ed. Bailliere Tindal, Pp. 17-63.

Schanzel, H. (1959). Age and lungworm infestation. Vet. Bull 29, 569.

Sissay, A. (1996). Preliminary study on the prevalence of ovine lungworm infection in and around Bahir Dar. DVM-Thesis, FVM, Addis Ababa University, Debre Zeit, Ethiopia.

Soulsby, E. J. L. (1982). Helminths, Arthropods and protozoa of Domesticated Animals 7th ed. Bailliere Tindal, London.

Teffera, S. (1993). Prevalence of ovine lungworms around Dessie and Kombolcha. DVM-Thesis, FVM, Addis Ababa University, Debre Zeit, Ethiopia.

Thomson, E. F, \& Orita, G. (1988). Seasonal prevalence of protostrongylid and Dictyocaulus species of lungworms in Awassi sheep in North-west Syria. Tropical animal health and production, 20(3), 187-189.

Thrusfield, M. (2005). Surveys in veterinary Epidemiology (2ndedn) Black well science Ltd, Cambridge, USA, Pp. 178198.

Torncy, P. M. (1989). Mannual of Tropical veterinary parasitology. Helminths of Livestock and poultry in Tropical Africa. The International Technical Center for agricultural and Rural co-operation, C.A.B. International, Pp. 81-85.

Urquhart, G. M., Armour, J., Duncan, J. L., \& Jenning, F. W. (1994). Veterinary Parasitology. Longman English language Society, Pp. 39-58.

Wendewosen, T. (1992). Prevalence of lungworms in ovines in and around Asela. DVM-thesis, FVM, Addis Ababa Unversity, Debre Zeit, Ethiopia. 